\title{
LOW GENETIC DIVERSITY IN THE ENDANGERED POPULATION OF VIOLA ULIGINOSA IN ITS LOCUS CLASSICUS AT RZAॄSKA NEAR CRACOW (SOUTHERN POLAND) AS REVEALED BY AFLP MARKERS
}

\author{
ElŻBIETA CieŚlak, WojCIECH PAUl, Michą RoniKIER \\ W. Szafer Institute of Botany, Polish Academy of Sciences \\ Lubicz 46, 31-512 Kraków, Poland \\ e-mail: cieslak@ib-pan.krakow.pl
}

(Received: November 11, 2005. Accepted: March 3, 2006)

\begin{abstract}
An extremely endangered population of Viola uliginosa Besser at the classical locality of this taxon has been studied. The AFLP analysis was based on 18 specimens of $V$. uliginosa (about $10 \%$ of preserved individuals); additionally, two individuals of $V$. riviniana were included in the data set as the out group. A high genetical uniformity of the whole population (similarity indexes close to 1) was detected. It was not correlated significantly with the spatial distribution of the plants. The study serves as a basis for practical conservation measures and at the same time as a starting point for a more extensive research on the genetical variability of the species throughout its range.
\end{abstract}

KEY WORDS: Viola uliginosa, conservation, rare and threatened plants, wet habitats, genetic structure of population, AFLP markers.

\section{INTRODUCTION}

The Viola uliginosa Besser range encompasses mostly the northern and the eastern parts of Central Europe (with conspicuous concentration of localities around the southern Baltic Sea), including also Belarus, as well as western Russia and western Ukraine. Additionally, single stations are (or were) known from Poland, eastern Germany, Czech Republic, Slovenia and northern Croatia (Hultén 1950, Meusel et al. 1978; Fig. 1). In all the mentioned countries, $V$. uliginosa is regarded at least as a rare and endangered plant, in some (eg. Czech Republic) as doubtful or even extinct (Kirschner and Skalický 1990).

Viola uliginosa was reported from several localities in Poland during the last century (Zabłocki 1947; Fig. 2). Although four populations were still known to exist in the last 30 years, only two of them were confirmed during works on the Polish Red Data Book of Plants (Baryła and Kuta 2001). The only well known and regularly observed population was that in Rząska near Cracow (S Poland; Fig. 3), from where the species was originally described by Besser (1809). The second locality (in SE Poland) was confirmed in 2000, yet no detailed information was available (Baryła and Kuta 2001). In consequence, and due to disappearance of the suitable habitats (wet meadows, fens and wet places in open (especially Alnus) forests on small rivers and brooks), V. uliginosa has been included into the "Critically Endangered" (CR) IUCN category in Poland (Baryła and Kuta 2001). The population at the locus classicus is included in the Polish nature monitoring programme. Lately, a new station has been found by two of the authors (Cieślak et al. 2004); that population will be included into further research.

Scarcity of the extant populations and the threat of their habitats may result in a situation when the only rational way to preserve the species will be an ex situ conservation (germplasm banks, botanical gardens, substitute localities). The fundamental condition for success of such actions is a precise establishment of the genetical variability range of the population to be preserved (or, if possible, of all the populations of the species over a definite area - a country or even the whole range). This allows establishing a minimum size of the sample to be collected in order to preserve also that variability. The too narrow (i.e. not reaching a threshold characteristic for every taxon in given conditions) intraspecific diversity results in a too small elasticity of the "answer" of the taxon to environmental changes, and therefore puts directly in danger this taxon's survival. The genetic studies of Viola uliginosa population from the locus classicus, initiated lately by the authors, are therefore of 


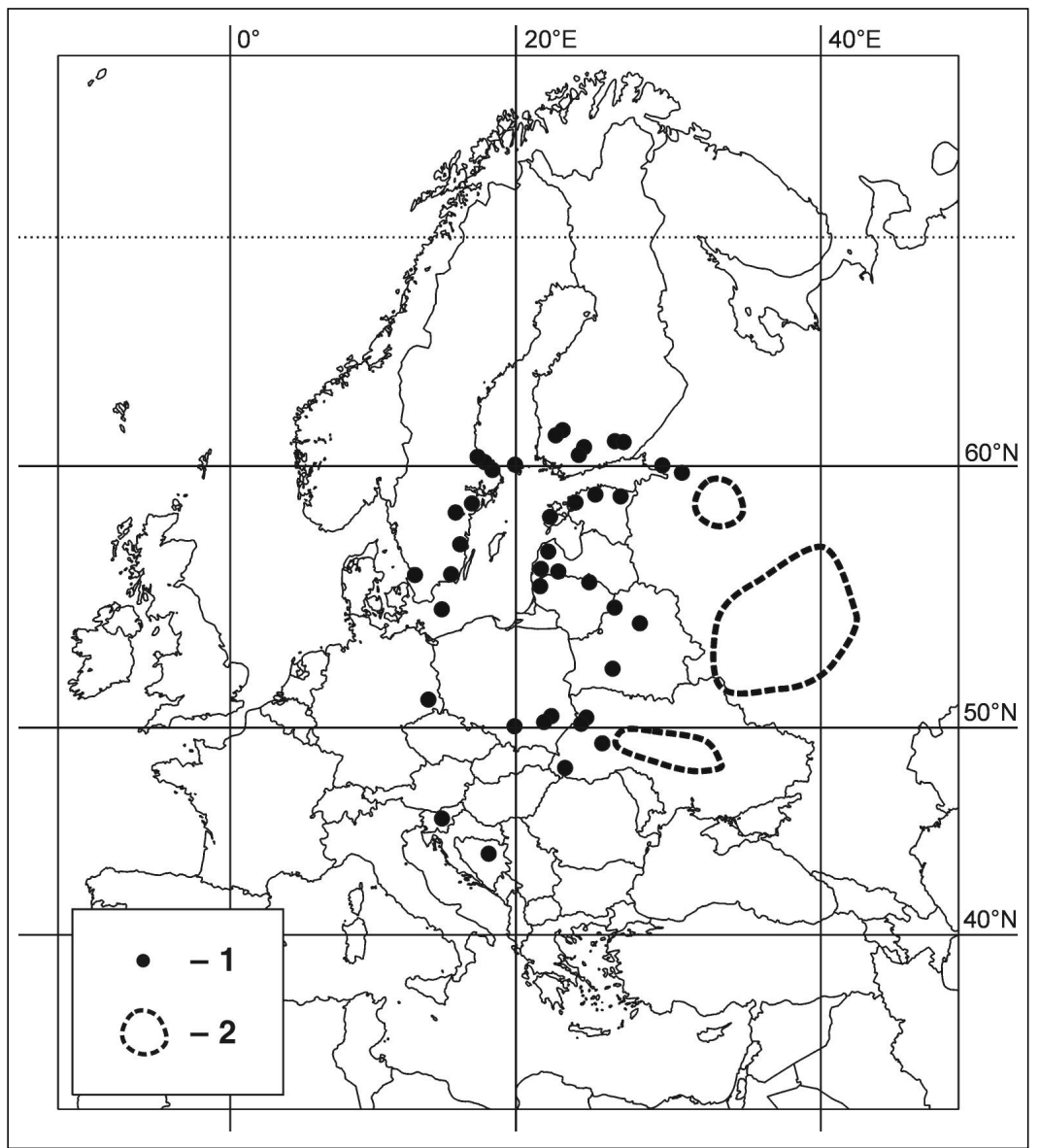

Fig. 1. Present general distribution of Viola uliginosa (after Hultén 1950; Meusel et al. 1978, modified): 1 - discrete localities; 2 range parts without precise locations given. utmost importance for the conservation measures planning, as well as for the taxonomy of the species. It shall serve a good starting point for more extensive research on $\mathrm{V}$. uliginosa over broader range. Consequently, the aims of this pilot study may be summarized as follows: (i) to estimate

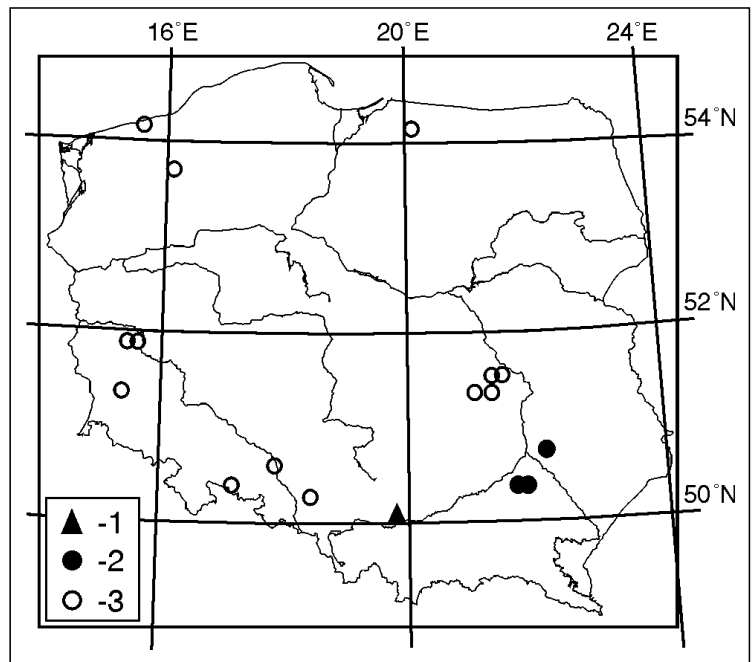

Fig. 2. Distribution of Viola uliginosa in Poland (after Baryła and Kuta 2001; Zając and Zając 2001, corrected and modified): 1 - studied locality; 2 - extant (confirmed) localities; 3 - historical and doubtful localities. the level of genetic variability in the population; (ii) to study relations between individuals and influence of presumably prevailing clonal growth in shaping the distribution of the genetic variability; and (iii) to estimate the reliability of AFLPs in Viola uliginosa and to test and establish specific AFLP technical parameters as a starting point for a wholerange genetic analysis of this species.

\section{MATERIALS AND METHODS}

\section{The population studied}

The studied population is presently composed by few separate groups. In total, approx. 150 individuals (in this number about 50 flowering) were found in 2002. In 1977 (before threat factors such as terrain drainage, construction of houses in close vicinity and subsequent change in water level started in 1980s), the population was considerably more numerous and covered a much larger area (E. Kuta, pers. inf.). In 1988, 120 flowering plants were counted (Baryła and Kuta 2001) which suggests that total number of plants was still considerably higher than at present. Due to habitat disturbance, the population size is continuously declining.

Cyto-embriological aspects of this, as well as other Polish populations were extensively studied by Kuta (1978). This author confirmed, that in Poland, like over its whole range, Viola uliginosa is a diploid of $2 \mathrm{n}=20$. Based on the 

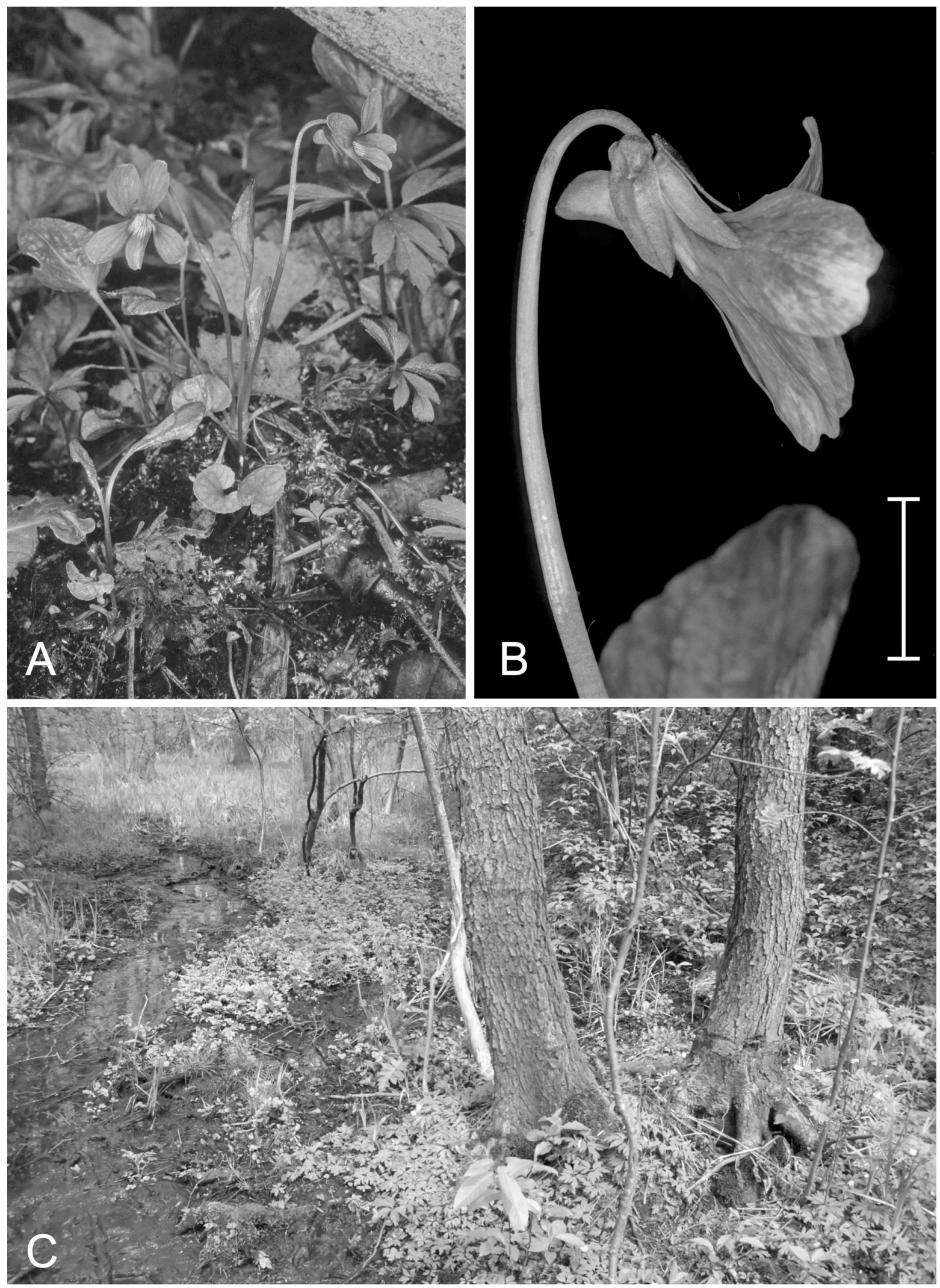

Fig. 3. Viola uliginosa at Rząska locus classicus: A - habitus; B - close-up of the flower; clearly visible are characteristic features of the species: the downwards-curved sporn and a 'marble' pattern of petals' colouring (scale bar $=1 \mathrm{~cm}$ ); C - fragment of the habitat (vicinity of S1 group, see Fig. 4A): Fraxino-Alnetum association. All photos by W. Paul. 


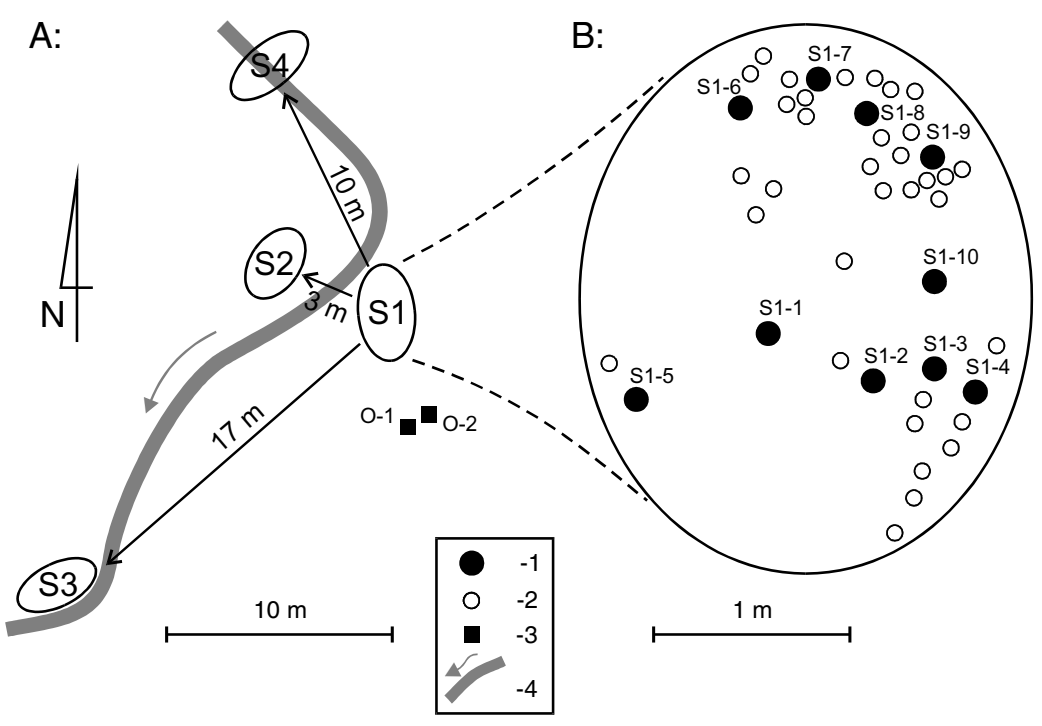

Fig. 4. Spatial relationship of the four Viola uliginosa subpopulations studied (A) and distribution of specimens studied within the subpopulation no. 1 (B); 1 - specimens sampled; 2 - specimens unsampled; 3 - outgroup specimens (V. riviniana); 4 - stream. biology of the species (mode of growth, i.e. forming young plants on long, short-lived subterraneous plagiotropic stems), that determines the great role of the vegetative way of propagation (Zabłocki 1947; Valentine et al. 1968), it may be regarded to a high degree as a clonal plant.

\section{Plant material}

Samples of 18 individuals of Viola uliginosa were collected in May 2002 from the locus classicus of the species in Rząska off Kraków. Specimens were chosen from 4 plant groups well defined in space and 3-17 m distant one from another (cf. Fig. 4). Within groups, different cases were considered in sampling (distant individuals, neighbouring individuals) in order to encompass sufficiently the spatial structure of the population within the sample set. The sampling applied in the present study had to be, however, a hard compromise between optimal statistical approach and high conservation needs. Approximately, 10-15\% of individuals were sampled for genetic analysis. Additionally, samples from 2 individuals of Viola riviniana Rchb. from neighbouring population were collected as analysis outgroup. Single young leaves (1-2 leaves per plant) were cautiously removed and put into hermetic plastic bags with silica gel for quick drying. Dried samples were stored at $-80^{\circ} \mathrm{C}$ before extraction of DNA.

\section{Extraction of DNA and AFLP analysis}

Dried leaf tissue (ca. 30-40 mg per sample) was ground after freezing in liquid nitrogen. DNA extraction and washing was performed using the DNeasy Plant Mini Kit system (Qiagen), according to the protocol provided by the manufacturer. Concentration and quality of the extracted DNA were checked using the GeneQuant spectrometer (Amersham Biosciences). AFLP analysis was carried out following the method of Vos et al. (1995) with modifications according to Bednarek et al. (1999). The genomic DNA (0.5 $\mu$ g per sample) was digested with the restriction enzymes EcoRI and MseI. Resulting fragments were ligated with respective adapter oligonucleotides to generate template DNA for PCR amplification. The PCR amplification was conducted in two steps (preselective and selective amplification). The restriction-ligation mixture was diluted

TABLE 1. Information conveyed by 12 primer combinations employed to detect AFLP marker for 18 individuals of Viola uliginosa.

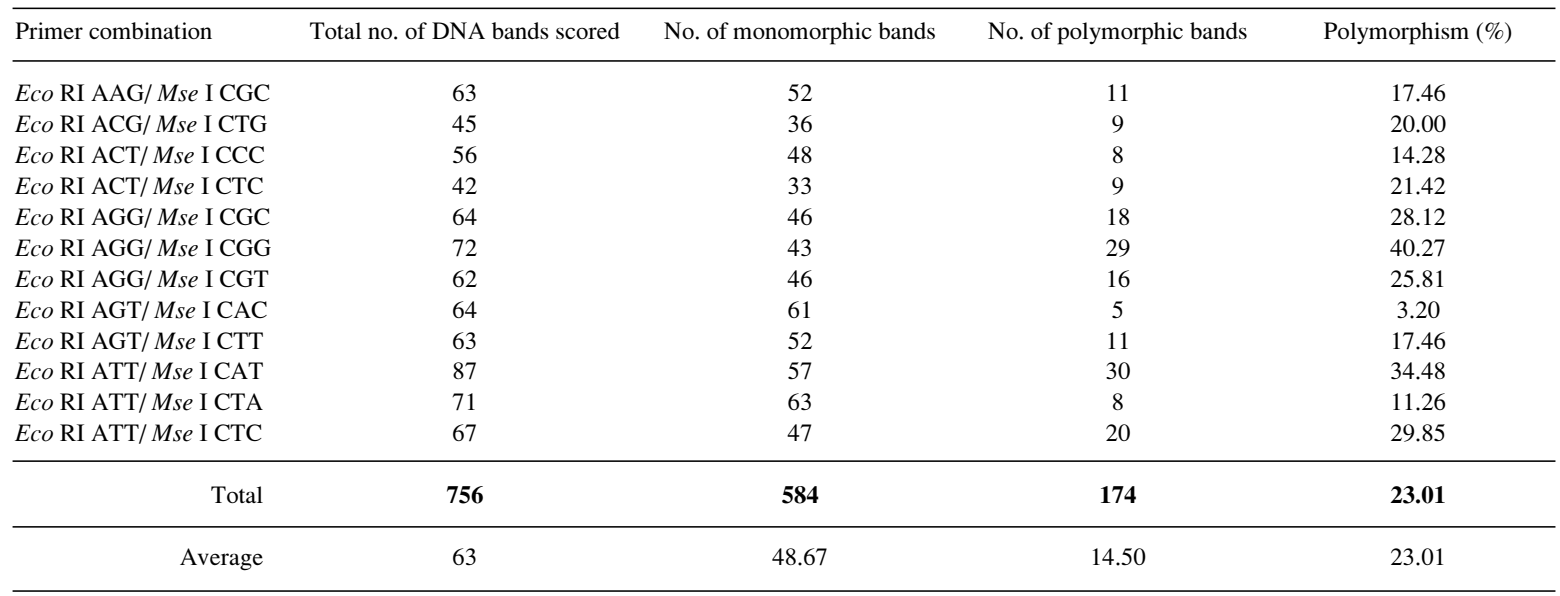


TABLE 2. Similarity coefficients for AFLP data of the studied population of Viola uliginosa using the UPGMA and WPGMA clustering methods.

\begin{tabular}{lccc}
\hline \multirow{2}{*}{ Clustering method } & & Coefficient used & \\
\cline { 2 - 4 } & Jaccard & Nei and Li's & Simple matching \\
\hline UPGMA & $0.899-0.989$ & $0.947-0.994$ & $0.906-0.990$ \\
WPGMA & $0.895-0.989$ & $0.945-0.994$ & $0.902-0.990$ \\
\hline
\end{tabular}

1:6 in deionized water prior to amplification. Preselective fragment amplification was performed with primers matching the adapter sequences supplemented by one additional selective nucleotide at the 3' end (EcoRI - A; MseI C). After a 20 -fold dilution step, the preselective PCR products were used for the second selective amplifications with two additional selective nucleotides added at primers' 3 ' ends. The selective EcoRI primers were labeled with ${ }^{32} \mathrm{P}$. Twelve primer pair combinations were used for selective amplification (Table 1). The resulting products of the selective amplification were separated on $8 \%$ denaturing polyacrylamide gels. The gels were incubated with X-ray films (Kodak) at $-30^{\circ} \mathrm{C}$ for $24-48 \mathrm{~h}$ to visualise band patterns autoradiographically.

\section{Data analysis}

AFLP bands were scored as present (1) or absent (0) for each sample and the data matrix gathering all data was generated. Intrapopulational relationships were estimated based on a similarity matrix. UPGMA and WPGMA cluste- ring methods were applied with the Jaccard (1908) and Nei and Li's (1979) similarity coefficients, as well as simple matching (Sokal and Michener 1958). Relationships between individuals were also studied using a principal coordinates analysis (PCO). Clustering methods, similarity coefficients and PCO were calculated using the NTSYS-PC software, version 2.0 (Rohlf 1997). Private fragments, i.e. unique for respective subpopulations, were also noted.

\section{RESULTS}

\section{Genetic structure of the population}

18 individuals of Viola uliginosa and 2 of V. riviniana (outgroup) were analysed. AFLPs using 12 selective primer combinations generated 1106 scorable fragments; 621 $(56.15 \%)$ fragments were polymorphic between $V$. uligino$s a$ and $V$.riviniana. For 18 individuals of $V$. uliginosa 756 AFLP fragments have been detected, 174 of which (23.01\%) were polymorphic (Table 1). In the UPGMA



Fig. 5. UPGMA dendrograms (Nei and Li's coefficient) showing similarity relationships among studied 18 specimens of Viola uliginosa with (A) and without (B) outgroup (two V. riviniana specimens) included; the high similarity coefficient values can be observed. 




Fig. 6. PCO scatter diagram for the 18 specimens of Viola uliginosa, from four subpopulations (S1-S4; cf. Fig. 4) studied.

(unweighted pair grouping method of arithmetic averages) and WPGMA (weighted pair grouping method of arithmetic averages, Sneath and Sokal 1973) analyses, ranges of similarity coefficients were similar, but the combinations of Nei and Li's similarity with UPGMA clustering yielded the highest cophenetic correlation. Comparison of similarity generated through alternative methods (Table 2) did not reveal any differences in the phenetic dendrograms (data not shown).

Based on the statistical analysis, a dendrogram was constructed by employing UPGMA, in order to group individuals into discrete clusters according to the similarity coefficient. This also provided an outgroup in cluster analysis of genetic similarity. Individuals of $V$. uliginosa grouped in subclusters, with the similarity coefficient ranging from 0.94 to 0.99 , except for one individual which separated from the rest with the value of 0.89 . Only limited correspondence with spatial distribution between individuals of $V$. uliginosa could be observed; four patches where samples had been collected were only moderately recognizable in the genetic structure of the population investigated (Fig. 5). Relationships among individuals within the population of $V$. uliginosa were also studied with the PCO. On the scatter diagrams (Fig. 6) along the first two axes, most individuals (15) from all patches composed one group close to the center of the PCO plot and the remaining three individuals (all belonging to the first subpopulation) were separated from this group. That analysis of the investigated population did not allow to identify any distinct spatial structure, even though the first three axes extracted altogether a large proportion (above 51\%) of the total variation $(32.47 \%, 11.13 \%$ and $8.98 \%$ respectively). The first and the second axes separated the same individuals as the UPGMA clustering analysis.

\section{DISCUSSION}

Our analysis showed a very high genetic uniformity of the collected material. Although each individual in the population had its own genotype profile, most plants were ve- ry close one to another with high similarity indexes. Differences between the single most distant genotypes hardly exceeded $10 \%$ and for the majority of genotypes it kept around the 5\% threshold and had a similarity coefficient higher than 0.96 (Fig. 5).

Results of these preliminary studies are congruent with ecological data (clonality) in respect to low polymorphism of the population. The expected high spatial structuring of the diversity, however, was not found. It could suggest an influence of the gradual (observed for several tens of years) decline of the population on impoverishment of its gene pool. Possibly complex multiclonal relationships from the past remained only in small groups of intermingled plants sometimes exhibiting a higher degree of distinction (vestiges of formerly more widespread old clonal groups?).

The most striking is the fact, that the major part of the observed variability was due to only two individuals (nos. S1-1, S1-4) occurring within the group characterized by the highest dispersion of individuals (Fig. 4B), while all the remaining samples (even those derived from various patches) showed a high degree of the genetical homogeneity. Two hypotheses can be considered here. The first one may attribute the considerable difference of the two individuals mentioned to earlier hybridization events, i.e. that we can observe now traces of introgression of alien violet species into the $V$. uliginosa genome. Rare hybrids of $V$. uliginosa and $V$. riviniana were observed indeed in the locality (Kuta 1978). However, the detailed comparison of AFLP marker bands of the two individuals in question with those of the neighboring $V$. riviniana specimens did not support the genetic introgression hypothesis (complete lack of $V$. riviniana-specific markers in their profiles). The second scenario takes into account possible impacts of clonality on the present structure; highly uniform patches are situated close to the bank of the stream and they could originate from distant propagation by water of one "paternal" genet, while individuals more spatially distant from there may reflect the formerly much more complex clonal structure (vestiges of old and mostly disappeared genets). The observed effect would suggest the present population being a small and depauperated remnant of the once more abundant (and thus differentiated) population.

The analysis of spatial distribution of genetic diversity in the population allows to provide guidelines for possible ex situ conservation. Due to a low diversification (majority of individuals did not possess any specific markers) and lack of spatial structuring, random sampling seems to be the best method to grasp the representative, still existing part of the population's variability.

Apart from conservation purposes, the present study provides important information source for taxonomy, preserving genetic material of Viola uliginosa from the locus classicus and thus ensuring reference data for taxonomic studies in case of disappearance of the type population. As it was already mentioned above, no traces of possible introgression from the side of the neighboring, profuse population of $V$. riviniana has been observed, that implies a low potential vulnerability of the studied population of $V$. uliginosa (and probably also the entire species) to 'dissolving' of the gene pool due to hybridization with other species of the genus that may be present in the vicinity. This conclusion is important when considering the taxonomical value of this population as a reference for $V$. uliginosa genetic status. 
The detailed discussion and more exhaustive inferences about the actual state of the locus classicus population of Viola uliginosa, will only be possible after including the material both from neighboring populations and from remaining parts of the general range (Germany, Sweden, Finland, Baltic states, Ukraine). This will enable comparison of the structure of genetic variability in populations from the border of the range (to which Rząska population belongs) with that observed in populations from its central part.

\section{ACKNOWLEDGMENTS}

The authors thank the anonymous reviewer for useful comments improving the manuscript. The research was supported by the State Committee for Scientific Research (KBN) grant no 2P04G 031 27. Scholarship of the Foundation for Polish Science to Michał Ronikier (2003-2004) is greatly acknowledged.

\section{LITERATURE CITED}

BARYŁA J., KUTA E. 2001. Viola uliginosa Besser. In: Polish red data book of plants. Kaźmierczakowa R., Zarzycki K. (eds) W. Szafer Institute of Botany, Polish Academy of Sciences, Kraków, pp. 245-247. (in Polish with English summary)

BEDNAREK P.T., CHWEDORZEWSKA K., KRÓLICZAK J., PUCHALSKI J., ZAWADA M. 1999. AFLP molecular markers as tools for genetic variability studies of rye inbred lines. Biul. Inst. Hod. Aklim. Rośl. 211: 219-227.

BESSER W.S. 1809. Primitiae florae Galiciae Austriacae utriusque. Pars 1, 2. Sumptibus Ant. Doll, Vienna.

CIEŚLAK E., PAUL W., CIEŚLAK J. 2004. Bogate stanowisko Viola uliginosa (Violaceae) w Kotlinie Sandomierskiej. Fragm. Florist. Geobot. Polonica 11 (1): 206-209. (in Polish with English summary)
HULTÉN E. 1950. Atlas of the distribution of vascular plants in N.W. Europe: 326 (map 1267). Stockholm.

JACCARD P. 1908. Nouvelles recherches sur la distribution florale. Bull. Soc. Vaud. Sci. Nat. 44: 223-270.

KIRSCHNER J., SKALICKÝ V. 1990. Viola L. - violka. In: Květena České Republiky. Hejný, S., Slavík, B. (eds). Academia, Praha, Vol. 2, pp. 394-431. (in Czech)

KUTA E. 1978. Cyto-embryological studies on the species of the Viola L. genus, Nomimium Ging. section from the territory of Poland. Fragm. Florist. Geobot. 24 (1): 23-91. (in Polish with English summary)

MEUSEL H., JÄGER E., RAUSCHERT S., WEINERT E. 1978. Vergleichende Chorologie der zentraleuropäischen Flora. Band II, Karten, 290. VEB Gustav Fischer Verlag, Jena.

NEI M., LI W.-H. 1979. Mathematical model for studying genetic variation in terms of restriction endonucleases. Proc. Natl. Acad. Sci. USA 76: 5269-5273.

ROHLF F.J. 1997. NTSYS-pc: numerical taxonomy and multivariate analysis system, version 2.0. Exeter Software, Setauket, NY.

SNEATH P.H.A., SOKAL R.R. 1973. Numerical taxonomy. The principles and practice of numerical classification. W.H. Freeman and Company, San Francisco.

SOKAL R.R., MICHENER C.D. 1958. A statistical method for evaluating systematic relationships. University of Kansas Scientific Bulletin 38: 1409-1438.

VALENTINE D.H., MERXMÜLLER H., SCHMIDT A. 1968. Viola L. In: Flora Europaea. Tutin T.G., Heywood V.H., Burges N.B., Valentine D.H., Walters S.M. and Webb D.A. (eds). University Press, Cambridge, p. 275.

VOS P., HOGERS R., BLEEKER M., REIJANS M., VAN DE LEE T., HORNES M., FRIJTERS A., POT J., PELEMAN J., KUIPER M., ZABEAU M. 1995. AFLP: a new technique for DNA fingerprinting. Nucl. Acids Res. 23 (21): 4407-4414.

ZABŁOCKI J. 1947. Violaceae. Flora polska 6: 1-70. PWN, Warszawa. (in Polish)

ZAJAC A., ZAJĄC M. (eds) 2001. Distribution atlas of vascular plants in Poland. Laboratory of Computer Chorology, Institute of Botany, Jagiellonian University, Cracow, p. 592. 